\title{
Konsep Teologis Perempuan Sundal di dalam Kitab Hosea
}

\author{
Rahel Cynthia Hutagalung \\ Sekolah Tinggi Teologi Baptis Indonesia Semarang \\ rahelcynthia@gmail.com
}

\begin{abstract}
ABSTRAK
Kitab Hosea merupakan kitab dalam perjanjian lama yang ditulis oleh Hosea. Hosea adalah seorang nabi yang menjadi saksi sebuah kemakmuran di masa Yerobeam II (793 - 753 SM). Hal yang menarik dalam kitab Hosea ini adalah Hosea tidak hanya menyampaikan pesan Allah dengan nubuatan saja, tetapi ia melakukan sebuah tindakan simbolik yang bertujuan melengkapi pesan - pesan nubuatannya. Pernikahannya dengan wanita sundal bernama Gomer menjadi simbolik hubungan bangsa Israel saat itu dengan Allah.
\end{abstract}

Kata kunci: Wanita Sundal, Nabi Hosea, Seni Kenabian Hosea, dan Keinginan Allah

\section{PENDAHULUAN}

Nabi Hosea adalah anak laki - laki dari Beeri dan merupakan penduduk Israel selama abad keemasan raja Yerobeam II. Arti dari nama Hosea itu adalah pertolongan atau kelepasan. Nama itu diambil dari bahasa Ibrani, yang berarti keselamatan / "Yesus" atau "Yeshua". ${ }^{1}$ Hosea adalah seorang nabi yang dimana mendapatkan suatu penglihatan dan nubuat - nubuat yang mereka utarakan adalah pesan dari Allah kepada umat pilihanNya. ${ }^{2}$ Kerajaan Israel menuju keruntuhan saat setelah kematian raja Yerobeam II, dan dimulailah suatu periode kekacauan besar.

Israel sudah menjadi jauh dari ibadah yang murni, sistem religinya beralih kepada penyembahan berhala dan kepada dewa dewa Kanaan (teristimewa Baal). ${ }^{3}$ Ketika Hosea memulai pelayanannya pada masa akhir pemerintahan Yerobeam II, Israel sedang mengalami kemakmuran ekonomi dan kestabilan politik, yang untuk

\footnotetext{
${ }^{1}$ John H Hill, Andrew E and Walton, Survei

Perjanjian Lama, ed. Triyogo Setyatmoko (Malang: Gandum Mas, 2009), 582.

2 Timothy Tow, The Minor Prophets (Singapore:

Far Eastern Bible College Press, 2001), 11.

${ }^{3}$ Leon J. Wood, The Prophets of Israel (Malang:

Gandum Mas, 2005), 401-6.
}

sementara waktu, hanya menciptakan rasa aman yang palsu. Dalam buku Kitab Nabi - Nabi Perjanjian Lama dijelaskan pelayanan Hosea kemungkinan terbentang sedikitnya selama tiga dekade, mungkin 752 hingga 724 SM, dari tahun - tahun akhir pemerintahan Yerobeam II hingga tahun - tahun terakhir kerajaan Israel. ${ }^{4}$ Satu-satunya alasan penugasan profetik kepada Hosea adalah karena Kerajaan Israel telah meninggalkan Tuhan Allah, dengan berpaling kepada para Baal, penyembahan berhala dan hidup dalam kejahatan - kejahatan. ${ }^{5}$ Tetapi dibalik semua hal tersebut, Hosea juga diutus untuk memberitakan pemulihan dari Tuhan. Jadi ada dua sisi di dalam misi pelayanannya, bernubuat menyatakan hukuman Tuhan dan menyampaikan bahwa ada pengharapan yang akan datang setelah malapetaka berakhir.

Bagian yang sangat menarik dalam pelayanan kenabian Hosea yakni kehidupan dan profesi Hosea sedemikian rupa sehingga orangorang sezamannya menyebutnya "pandir" atau orang gila. ${ }^{6}$ Hal itu terjadi karena tindakannya -

\footnotetext{
${ }^{4}$ C Hassell Bullock, Kitab Nabi - Nabi Perjanjian Lama (Malang: Gandum Mas, 2009), 117.

${ }^{5}$ Hill, Andrew E and Walton, Survei Perjanjian Lama, 584.

${ }^{6}$ Bullock, Kitab Nabi - Nabi Perjanjian Lama. 115
} 
atas perintah Allah -- menikahi seorang perempuan sundal bernama Gomer. Sejatinya, nabi memiliki posisi terhormat di dalam lingkup sosio historis Israel, dan dianggap mewakili Tuhan dan representasi hidup kudus. Kenyataannya, Hosea bertindak tidak lazim selayaknya nabi. Masyarakat saat itu menganggap tindakan yang dilakukan Hosea untuk menikahi seorang perempuan sundal, dianggap sebagai tindakan yang menjatuhkan diri sendiri, dan tentu saja menjadi bahan ejekan. Kehidupan yang ditampilkannya bertolakbelakang dengan asumsi kehidupan nabi yang selama ini diyakini masyarakat.

Akan tetapi, situasi perkawinan Hosea justru menjadi bagian dari panggilan kenabiannya untuk kerajaan Israel. Sikap dan tingkah laku Gomer merupakan sebuah analogi dalam cara Tuhan menggambarkan hubungannya dengan Israel. Sebagaimana Gomer yang tidak setia dan hidup dalam perzinahan, demikian Allah menggambarkan perzinaan rohani Israel dan pelanggaran-pelanggaran yang dilakukan bangsa tersebut terhadap perjanjian kudus denganNya. Pokok pikiran inilah yang menjadi pembahasan di dalam paper ini, khususnya di dalam mengangkat makna teologis pernikahan Hosea dengan perempuan sundal dan kaitannya dengan hubungan antara Allah dan Israel.

\section{METODE PENELITIAN}

Tulisan ini disusun dengan melakukan penelitian dokumen di dalam buku - buku dan artikel jurnal dalam suatu penelitian kepustakaan. Data-data berupa teori dan konsep digunakan sebagai alat analisis untuk melakukan pembahasan topik dan sub topik. Pendekatan yang dipergunakan adalah penelitian historis, yaitu bentuk penelitian yang memiliki tujuan untuk menggambarkan fakta sejarah dan menarik kesimpulan atas kejadian masa lalu. ${ }^{7}$ Pendekatan khusus untuk sastra hikmat orang Ibrani juga dilakukan untuk

\footnotetext{
${ }^{7}$ P. Mark L. Sandercock, "How to Write and Publish a Scientific Article," Journal of the Canadian Society of Forensic Science 45, no. 1 (2012): 1-5,

https://doi.org/10.1080/00085030.2012.10757179.
}

tujuan memahami konteks terhadap simbol dan gambaran (imagery). ${ }^{8}$ Semua sumber-sumber tersebut direkonstruksi untuk menemukan makna teologis dari kehidupan Hosea dan Gomer dalam pelayanannya sebagai nabi bagi Israel Utara.

\section{PEMBAHASAN}

Deskripsi yang diungkapkan di dalam kitab mengenai perempuan yang diperintahkan Tuhan untuk dikawini oleh Hosea sangat lugas. Perempuan bernama Gomer itu digambarkan sebagai sosok perempuan yang tidak setia dan berprofesi seorang pelacur atau di dalam termonologi kitab disebut sebagai perempuan sundal. Statusnya yang seperti itu terlihat sengaja ditampilkan pada bagian awal kitab sebagai pengantar untuk memberikan tekanan pada maksud utama pengutusan Hosea kepada Israel, bangsa yang "buruk rupa" dihadapan Tuhan. ${ }^{9}$ Pemaparan tentang status wanita ini tergolong berani dan tidak ditutup-tutupi. Seluruh narasi didalamnya terlihat sangat deskriptif.

\section{Mengapa Perempuan Sundal?}

Hubungan Allah dengan Israel sering kali disamakan dengan ikatan pernikahan (Lihat misalnya Yesaya 54:5, Yeremia 3:14, Efesus 5 :22-32). Gambaran hubungan pernikahan ini sangat intim dan kudus dengan menampilkan eksistensi Allah sebagai suami dan bangsa Israel saat itu sebagai istri. Akan tetapi hubungan tersebut tidak berjalan baik. Israel beralih kesetiannya kepada dewa-dewa dan baal sebagai berhala. Hal inilah yang mendukakan hati Tuhan dan digambarkan sebagai sebuah perzinahan rohani dari sebuah hubungan yang seharusnya terjaga dan kudus. Sebagai pihak yang lebih tinggi, Allah berinisiatif memperbaiki hubungan tersebut dan mengutus Hosea agar bangsa ini bertobat dan kembali pada hubungan yang kudus kepada Allah. Cara Tuhan mengutus Hosea dan menyampaikan isi hatiNya tergolong unik. Hosea diminta menjalani kehidupan keluarga

\footnotetext{
${ }^{8}$ Sonny Eli Zaluchu, "Pola Hermenetik Sastra Hikmat Orang Ibrani," Evangelikal 3, no. 1 (2019): 21-29.

${ }^{9}$ Robert Setio, "Menafsir Metafora Dalam Kitab Hosea," GEMA TEOLOGIKA 2, no. 2 (2017): 173-94, https://doi.org/10.21460/gema.2017.21.292.
}

Rahel Cynthia Hutagalung, Konsep Teologis... 
sebagai gambaran hubungan Allah-Israel. ${ }^{10}$ Inilah yang menjadi latar belakang perintah Allah kepada Hosea untuk pergi kepada perempuan sundal itu dan menikahinya. Ketika TUHAN mulai berbicara dengan perantaraan Hosea, berfirmanlah Ia kepada Hosea: "Pergilah, kawinilah seorang perempuan sundal dan peranakkanlah anak-anak sundal, karena negeri ini bersundal hebat dengan membelakangi TUHAN" (Hosea $1: 2$ ).

Firman yang diterima oleh Hosea merupakan perintah yang bersifat imperatif. Tidak ada pilihan lain kecuali menjalaninya. Pertanyaan yang menarik adalah, mengapa harus perempuan sundal? Sundal memiliki arti yang sama dengan kata "pelacur" yang menurut Kamus Besar Bahasa Indonesia online diartikan sebagai "jalang" yakni atribut perempuan yang menjual diri untuk memuaskan hawa nafsu. ${ }^{11}$ Seorang wanita sundal melakukan profesi kotor dan melanggar prinsip-prinsip moralitas. Profesi ini dijalankan baik secara terbuka dan terlebih secara tertutup. Kekejian yang muncul dari perilaku dosa seperti ini terlihat dari keputusan para perempuan yang menjalani profesi itu untuk tidak mau kawin, dan menarik keuntungan material dari tindakannya menjual diri.

Allah pasti punya alasan menggunakna profesi ini sebagai gambaran di dalam menjelaskan penyimpangan demi penyimpangan yang dilakukan oleh umat kesayanganNya. Sebagai sebuah penggambaran (imagery) sundal yang dimaksudkan dalam kitab Hosea adalah metafora dari bangsa Israel itu sendiri yang dianggap berperilaku sama dengan kesundalan.

Kata "Sundal" dalam ayat 2 pasal pertama kitab Hosea, diulang hingga 3 (tiga) kali, bahkan sampai empat kali di dalam teks Ibrani. Dengan demikian, sangat jelas maksud Allah tergambarkan di bagian awal kitab dan pemanggilan Hosea. ${ }^{12}$ Harus

\footnotetext{
${ }^{10}$ H Rothlisberger, Firmanku Seperti Api : Para Nabi Israel, 6th ed. (Jakarta: BPK Gunung Mulia, 2017), 19.

${ }^{11}$ KBBI, "Penelitian," Pusat Bahasa, 2017, https://kbbi.kemdikbud.go.id/entri/jalang.
}

dipahami bahwa persundalan yang dilakukan oleh perempuan - perempuan yang diungkap di dalam narasi PL (misalnya di dalam Kejadian 38, Yosia 2) memiliki makna yang agak berbeda ketika dipakai di dalam kitab nabi - nabi. Di dalam kitab-kitab PL tersebut ada sedikit perluasan makna dimana persundalan merupakan sinonim bagi istilah kemurtadaan. Bentuk persundalan yang paling berbahaya ialah persundalan yang disetujui oleh agama, ini merupakan ciri utama dalam kebaktian Kanaan, baik sundal laki - laki maupun perempuan dihubungkan dengan tempat - tempat suci. Sementara di dalam kitab nabi-nabi lebih mengarah pada tindakan seperti pelacur.

Beberapa penafsir melihat bahwa kehidupan yang dialami Hosea dengan perempuan sundal merupakan satu tragedi di dalam kehidupan sang nabi. Berita dari Allah yang diterimanya, bukan hanya untuk disampaikan tetapi juga harus dijalaninya. ${ }^{13}$ Tentu saja hal ini bukanlah sebuah kekeliruan. Sering kali disimpulkan, bahwa apa yang dilakukan pelacur adalah tindakan yang keji, liar dan diluar akal sehat. Tetapi, pandangan seperti ini keliru. Seorang pelacur tidak mesti berperilaku buruk. Cerita Rahab, pelacur di kota Yerikho yang menolong Yosua dan kawan-kawannya dari pengejaran raja Yerikho (Yosua 2) adalah contoh terbaik. Rahab jelas menunjukkan seorang yang peduli dan mau melindungi orang yang dalam bahaya dengan cara yang sebetulnya mengancam nyawanya dan sleuruh kaum keluarganya. ${ }^{14}$ Akan tetapi, hal yang sama tidak dapat dilihat di dalam kasus Gomer dan Hosea. Gomer menampilkan karakter pelacur yang memang benar-benar sebagai sebuah profesi, berdedikasi untuk mencari upah, atau dengan sebutan perempuan pelacur bakti. Istilah ini berlaku bagi wanitawanita yang menjual diri untuk mendapatkan upah dan kesenangan duniawi. Pernyataan ini didukung fakta, bahwa Hosea diminta Tuhan untuk mengawini Gomer untuk kedua kalinya sementara Gomer sendiri telah

\footnotetext{
12 Derek Kidner, The Message of Hosea, ed. Frans Balla (Jakarta: Yayasan Komunikasi Bina Kasih, 2000), 21.

13 John Drane, Memahami Perjanjian Lama II: Dari

Kerajaan Terpecah Sampai Pasca Pembuangan (Jakarta: Persekutuan Pembaca Alkitab, 2002), 25.

14 Setio, "Menafsir Metafora Dalam Kitab Hosea."
} 
meninggalkannya dan menjadi milik lakilaki lain. Hosea diminta menebus wanita itu dengan membayar sejumlah uang. ${ }^{15}$ Semua perbuatan Gomer seolah dilupakan. ${ }^{16}$ Tidak ada penjelasan apakah Hose berbahagia dengan pernikahannya itu tetapi, pasangan ini memiliki dua anak laki - laki dan satu anak perempuan. Masing-masing diberi nama Yizreel, Lo Ruhama,dan Lo Ami.

\section{Nabi yang Bernubuat dengan kekhasan}

Hubungan Hosea istrinya yang melacur, sebagaimana dikemukakan sebelumnya, adalah gambaran dari Israel yang tidak setia. Hubungan tersebut digambarkan secara dramatis sebagai penolakan Israel akan kasih Allah dan keinginan untuk membawa kembali bangsa yang "melacur" ke dalam hubungan yang benar dan kudus. ${ }^{17}$ Hosea bernubuat bukan hanya dengan kata-kata melainkan dengan hidupnya sendiri. Pesan nubuatannya terlihat dari kehidupan yang dijalaninya. ${ }^{18}$ Kidner mengatakan, apa yang harus dilakukan oleh Hosea adalah miniatur dari apa yang dilakukan oleh Tuhan, yakni memberikan kasihNya kepada pasangan yang memiliki masa lampau suram sekaligus mata keranjang, yang tidak bisa terlalu lama dibiarkan. ${ }^{19}$ Terlihat bahwa penyampaian nubuatan yang dilakukan oleh Hosea unik dan khas, sangat jauh berbeda dengan pemberitaan nubuatan yang dilakukan oleh nabi - nabi lainnya menjelang PL berakhir. ${ }^{20}$

Respon yang diperlihatkan Hosea dari setiap perintah Tuhan yang khas di dalam panggilannya patut diteladani. Tidak terdapat argumen di dalam narasi bahwa Hosea menolak atau paling tidak mempertanyakan perintah Allah. Hosea menjalani dengan penuh ketaatan, tanpa

\footnotetext{
${ }^{15}$ Drane, Memahami Perjanjian Lama II: Dari Kerajaan Terpecah Sampai Pasca Pembuangan, 26.

${ }^{16}$ Moshe Reiss, "Hosea: A Schizophrenic Prophet," Scandinavian Journal of the Old Testament, 2011, https://doi.org/10.1080/09018328.2011.574403.

${ }^{17}$ Hill, Andrew E and Walton, Survei Perjanjian Lama, 585.

18 "Social World of the Hebrew Prophets," Choice Reviews Online, 2013,

https://doi.org/10.5860/choice.40-1488.
}

merasa malu, tidak menghindar dan penuh dengan ketaatan. Hal ini terjadi karena keyakinan penuh bahwa sesuatu yang diberitakannya memang berasal dari Allah. Hosea juga terlihat memahami bahwa tujuan akhir dari semua itu adalah agar bangsa Israel sadar dan kembali kepada Allah.

Kalau Kitab Hosea terlihat menggunakan perempuan sebagai simbol dari sebuah pelanggaran dan kesalahan, dalam konteks yang sebenarnya, pandangan tersebut tidak tertuju kepada pribadi perempuan itu sendiri, melainkan kepada umat yang disimbolkan, yakni Israel sebagai bangsa. ${ }^{21}$ Itu sebabnya dapat disimpulkan bahwa sesungguhnya, pernikahan yang dijalani oleh Hosea kental dengan gambaran simbolik. Tujuan akhirnya sudah terlihat. Sekalipun penghakiman atas dosa dan pelanggaran Israel sudah pasti akan datang, Hosea berhasil mendemontrasikan dan mendeskripsikan kasih dan anugerah Allah melalui tindakan simbolik dari hidupnya sendiri. Pesannya jelas. Allah membenci dosa - dosa umatNya, Allah menyatakan penghakiman yang pasti tetapi Allah yang sama yang akan melakukan pemulihan. ${ }^{22}$ Tindakan simboliknya adalah sebuah peringatan penting yang harus disikapi dengan pertobatan, sehingga menjadi konkret apa yang telah dibuat bangsa itu terhadap Allah dan apa yang menjadi sikap Allah kepada bangsa tersebut. ${ }^{23}$

Nubuat yang dilakukan oleh para nabi, dapat dibagi menjadi dua kategori atau sifat. Dua kategori ini yakni sifat meramal dan sifat menghimbau. Nubuat yang bersifat meramal memberitakan hal - hal yang akan terjadi pada masa yang akan dekat hingga jauh, dan nubuat bersifat menghimbau memberikan nasihat, peringatan, teguran, ajaran. Sifat nubuat menghimbau ini juga yang dilakukan oleh nabi Hosea dalam memberikan nubuatannya kepada bangsa Israel. Hosea melakukan seni

\footnotetext{
${ }^{19}$ Kidner, The Message of Hosea, 22.

${ }^{20}$ Beate Ego et al., Biblia Qumranica : Minor Prophets (Leiden: BRILL, 2005).

${ }^{21}$ Setio, "Menafsir Metafora Dalam Kitab Hosea."

${ }^{22}$ Sonny Eli Zaluchu, Studi PL : Kitab 12 Nabi, 1st ed. (Semarang: Golden Gate Publishing Semarang, 2019), 62.

${ }^{23}$ ST Darmawijaya, Tindak Kenabian : Kisah Perbuata Aneh Para Nabi, 1st ed. (Yogyakarta: Kanisius, n.d.), 77.
}

Rahel Cynthia Hutagalung, Konsep Teologis... 
kenabiannya dengan sangat khas berupa sebuah prophetic act. ${ }^{24}$ Pernikahan Hosea adalah tindakan profetik kasih Allah yang tidak berkesudahan kepada umatNya, walaupun umatNya sudah bersundal dengan kekasih - kekasih asingnya yang lain. ${ }^{25}$ Prophetic act ialah sebuah tindakan profetik dimana nabi melayani dengan tindakantindakan yang maknanya bukan secara harafiah melainkan simbolik. Tindakan tersebut merupakan sebuah pesan kenabian. Di dalam mekanisme pelayanan para nabi di Israel, tindakan profetik seringkali menjadi warna tersendiri. Sebab, tindakan itu adalah sebuah simbol dengan makna khusus. Simbol diartikan sebagai lambang yang harus ditafsirkan dengan melihat secara keseluruhan misi yang sedang nabi jalankan..

Nabi Hosea adalah nabi pertama yang membandingkan persatuan Allah dengan Israel berdasarkan perjanjian yang diikat di gunung Sinai, melalui perkawinan. Karena itu nabi Hosea tidak hanya menyebut pemujaan dewa - dewa sebagai persundalan, tetapi sebagai tindakan zinah. Disinilah terletak kekhasan dan keunikan pelayanan Hosea. Bagi Hosea, persundalan yang dilakukan bangsa Israel mempunyai arti ganda. Umat itu bukan saja melakukan perzinahan rohani terhadap Allah dengan berpaling kepada Baal, tetapi mereka juga benar - benar melacurkan diri dalam perbuatan seks yang berhubungan dengan upacara penyembahan terhadap dewa kesuburan orang - orang Kanaan. ${ }^{26}$ Simbologi yang mencuat dari prophetic act Hosea mendapat legalitasnya dari perilaku orang Israel itu sendiri.

\section{KESIMPULAN}

Perintah Allah adalah kunci utama di dalam memahami pernikahan Hosea dengan Gomer. Misianya adalah kehendak Allah untuk menyadarkan bangsa Israel agar segera keluar dari ketidaksetiaannya dan kembali kepada Allah. Wanita Sundal yang menjadi tema ini adalah sebuah prophetic

\footnotetext{
${ }^{24}$ Zaluchu, Studi PL : Kitab 12 Nabi, 63.

${ }^{25}$ Dr. Barnabas Ludji, Pemahaman Dasar

Perjanjian Lama, 2nd ed. (Bandung: Bina Media Informasi, 2009), 60.
}

act dan simbol yang dilakukan Hosea dalam rangka mengemban mandat atas perintah Allah kepadanya. Seperti nabi - nabi lain yang melakukan tindakan - tindakan dan lambang dalam bernubuat, demikian juga yang terlihat melalui kehidupan Hosea. Hosea sampai dua kali mencintai seorang perempuan yang mengecewakan, dan mengkhianati dengan ketidaksetiaannya. Demikian juga sifat Tuhan yang panjang sabar dan selalu memberikan kesempatan demi kesempatan bagi lahirnya pertobatan sejati. Tentu saja tragedi yang dialami oleh Hosea adalah kunci dari berita atau pesan Allah yang disampaikan Tuhan bagi umatNya. Sebagaimana kasinya kepada Gomer, demikian kasih Allah digambarkan di dalam kehidupan Hosea.

Kitab Hosea memberi pesan yang kuat bagi kekristenan. Pernikahan nabi tersebut menjadi pelajaran tentang ketidaksetiaan kepada Tuhan. Meninggalkan Tuhan bukan hanya membawa kepada penyembahan palsu tetapi juga kepada menurunkan norma kesusilaan pada titik terendah. Orang-orang seperti Hosea akan Tuhan kirim untuk membawa penhakiman di satu sisi dan kasih Tuhan di sisi yang lain. Dibalik hukuman yagn dinyatakanNya tersedia kasih yang memulihkan.

\section{DAFTAR PUSTAKA}

Bullock, C Hassell. Kitab Nabi - Nabi Perjanjian Lama. Malang: Gandum Mas, 2009.

Darmawijaya, ST. Tindak Kenabian: Kisah Perbuata Aneh Para Nabi. 1st ed. Yogyakarta: Kanisius, n.d.

Drane, John. Memahami Perjanjian Lama II: Dari Kerajaan Terpecah Sampai Pasca Pembuangan. Jakarta: Persekutuan Pembaca Alkitab, 2002.

Ego, Beate, Armin Lange Lichtenberger, Hermann Troyer, and Kristin De. Biblia Qumranica: Minor Prophets. Leiden: BRILL, 2005.

Hill, Andrew E and Walton, John H. Survei Perjanjian Lama. Edited by Triyogo Setyatmoko. Malang: Gandum Mas, 2009.

\footnotetext{
${ }^{26}$ Hill, Andrew E and Walton, Survei Perjanjian Lama, 590.
} 
KBBI. "Penelitian." Pusat Bahasa, 2017. https://kbbi.kemdikbud.go.id/entri/pe nelitian.

Kidner, Derek. The Message of Hosea. Edited by Frans Balla. Jakarta: Yayasan Komunikasi Bina Kasih, 2000.

Ludji, Dr. Barnabas. Pemahaman Dasar Perjanjian Lama. 2nd ed. Bandung: Bina Media Informasi, 2009.

Reiss, Moshe. "Hosea: A Schizophrenic Prophet." Scandinavian Journal of the Old Testament, 2011. https://doi.org/10.1080/09018328.20 11.574403.

Rothlisberger, H. Firmanku Seperti Api : Para Nabi Israel. 6th ed. Jakarta: BPK Gunung Mulia, 2017.

Sandercock, P. Mark L. "How to Write and Publish a Scientific Article." Journal of the Canadian Society of Forensic Science 45, no. 1 (2012): 1-5. https://doi.org/10.1080/00085030.20 12.10757179.

Setio, Robert. "Menafsir Metafora Dalam Kitab Hosea." GEMA TEOLOGIKA 2, no. 2 (2017): 173-94. https://doi.org/10.21460/gema.2017.2 1.292.

"Social World of the Hebrew Prophets." Choice Reviews Online, 2013. https://doi.org/10.5860/choice.401488.

Tow, Timothy. The Minor Prophets. Singapore: Far Eastern Bible College Press, 2001.

Wood, Leon J. The Prophets of Israel. Malang: Gandum Mas, 2005.

Zaluchu, Sonny Eli. "Pola Hermenetik Sastra Hikmat Orang Ibrani." Evangelikal 3, no. 1 (2019): 21-29. - Studi PL: Kitab 12 Nabi. 1st ed. Semarang: Golden Gate Publishing Semarang, 2019. 